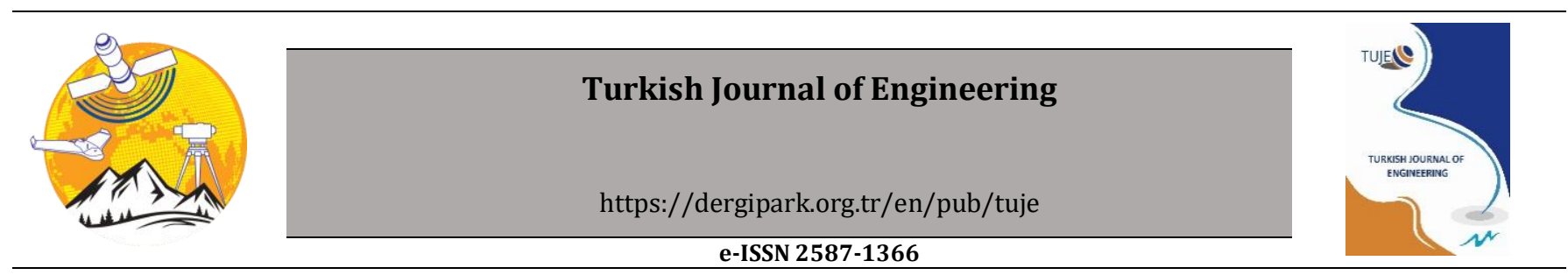

\title{
Lateral response of double skin tubular column to steel beam composite frames
}

\author{
Ahmed Dalaf Ahmed 1,2 ${ }^{\mathbb{D}}$, Esra Mete Güneyisi *2 ${ }^{\circledR}$ \\ ${ }_{1}^{1}$ Anbar University, Department of Civil Engineering, AL Anbar, Iraq \\ ${ }^{2}$ Gaziantep University, Department of Civil Engineering, Gaziantep, Turkey
}

\author{
Keywords \\ Double Skin \\ Composite Column \\ Composite Frame \\ Lateral Load \\ Numerical Analysis \\ ANSYS
}

\begin{abstract}
Concrete filled double-skin steel tubular (CFDST) column comprises two inner and outer steel tubes with infill concrete between tubes. CFDST columns are used in many structural systems such as offshore structures and high rise buildings. The aim of this research is to examine the performance of composite frames composed of CFDST columns and steel beam under the influence of lateral loading. The frames were modeled and analyzed utilizing ANSYS finite element (FE) software. The linear and nonlinear behavior of steel and concrete materials and confinement effects of inner and outer steel tubes on the infill concrete were considered in the analysis. Three key parameters were considered in the present study. They are the axial load and slenderness ratios of CFDST column as well as linear stiffness ratio of the beam-column. The effects of these parameters on the behavior of the composite frames were evaluated comparatively. Load-deformation responses were achieved for various cases of the investigation. The verification of the developed FE model was evaluated by considering the analysis results with the experimental data existing in the literature. The findings attained from the FE modeling were in consonance with the experimental results. Besides, it was observed that the above parameters had a substantial influence on the load-displacement relationship and the performance of the studied composite frames.
\end{abstract}

\section{INTRODUCTION}

Structural engineers aim to efficiently utilize the available construction materials. Composite structures, made of concrete and steel, take advantage of the strength characteristics of both materials. In this context, a column made of two concentric inner and outer steel tubes with concrete filled between tubes offers many advantages for the economic structural design. The two materials are mutually beneficial: the steel tubes confine the concrete, effectively rising its strength and ductility, avoiding the spalling of the concrete and protecting it from an accidental impact whereas the concrete delays the local buckling and prevent the sudden failure of the steel tubes. Concrete filled double-skin steel tubular (CFDST) columns provide technological benefits as well. Formwork and traditional reinforcement for the columns are no longer required, which significantly reduce material, labor costs and speed up the construction process. The use of steel tubes as erection columns, and filling the space between them with concrete at a later construction stage, combines the speed of conventional steel erection with the cost effectiveness of reinforced concrete structures. Additionally, there is an evidence of improving fire resistance of CFDST columns due to the infill concrete, which reduces the need for fire protection in many cases. The outer and inner tubes of CFDST may have the same or different cross-section shapes like square-circular, square-square, circular-circular, etc. (Ritchie et al. 2017, Hassanein et al. 2015).

In the literature, several researchers have been investigated the performance of these columns such as Wei et al. (1995), Yagishita et al. (2000), Zhao et al. (2002a, 2002b, 2002c, 2002d), Elchalakani et al. (2002), Bradford et al. (2002), Han et al. (2004), Han et al. (2006), and Uenaka et al. (2010). It has been concluded that the inner and outer tubes can give a reliable support to the infill concrete prior to the ultimate stress achieved. The CFDST column has more advantages compared with the CFST column, like less weight, more damping 
characteristics and cyclic behavior (Lu et al., 2010). Schematic view of CFDST column and its possible crosssection is illustrated in Fig. 1 while Fig. 2 shows the constructing CFDST column in high-rise structures (Li et al. 2012).
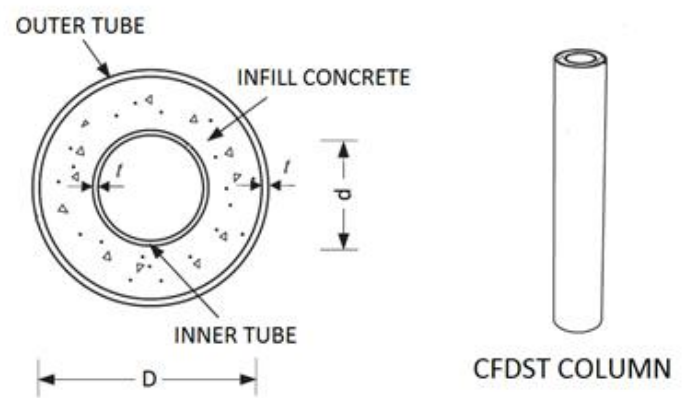

Figure 1. A typical CFDST column and its cross section (Li et al., 2012)

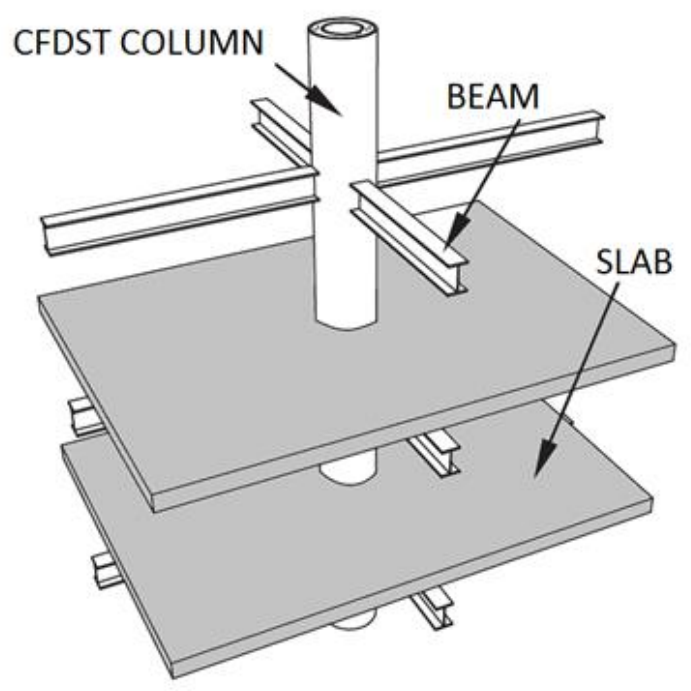

Figure 2. Constructing of CFDST column in a structure (Li et al., 2012)

In recent years, various investigations have been performed using finite element (FE) analysis to study the structural response of CFDST columns. For instance, Huang et al. (2010) modeled fourteen samples similar to those at first introduced by Lin and Tsai (2001) and Tao et al. (2004), seeking to inspect the consistency of the models using ABAQUS software. Based on the stressstrain relations, it was figured out that CFDST column with a higher confinement factor exhibited a strainhardening performance while a strain-softening response was noticed with small values of the confinement factor. In another study, Pagoulatou et al. (2014) modeled circular CFDST members using FE analysis. CFDST columns were loaded under concentric axial forces. Thus, to get an appropriate model of the columns, the recognition of material properties for the infill concrete and steel seemed to be very significant. Comparing the structural performance of the FE models with those of the experiments showed similar results.

Additionally, Zhang and Zhou (2019) studied the performance of the beam-column connections of CFDST frame structures. Many FE models were generated to analyze the behavior of the connections and major variables, which affect their performance. Generally, the design of the beam-column connections could take the advantages of double tubes in CFDST structure; therefore, several structural improvements for design parameters of connection in CFDST frames were suggested to improve the seismic performance of the connection. Zhang et al. (2018) presented an innovative connection to join the steel beam with a CFDST column. Four half-scale samples of beam-column connections were manufactured and loaded under an axial load with vertical low-reversal forces used on the beam edges to evaluate the failure mode and hysteretic behavior of the connections. The hinging mechanism of the connection was noticed in the horizontal end plates. The suggested beam-columns exhibited a great energy dissipations and rotations at the failure equal to $0.05 \mathrm{rad}$. The connection rotation satisfied the ductility condition of FEMA 350 for the seismic resistance which is greater or equal to 0.03 rad. FE models of the connections were developed and confirmed by comparing their results with the experimental ones. FE models were also utilized to examine the effect of many factors like the height of anchorage plates, axial force, steel and concrete strength, steel ratio on the moment-rotation relation, and stiffness of connections.

In this study, the structural response of composite frames with circular CFDST columns and steel beam under the influence of lateral loads was investigated. The frames were modeled and analyzed using ANSYS FE software (ANSYS, 2016). The impact of the ratios of the axial load and slenderness ratio of CFDST column together with the ratio of the linear stiffness of the beamcolumn on the lateral behavior of the composite frames was studied in a comparative manner. A total of sixteen models were developed and analyzed. The accuracy and effectiveness of the generated FE model was also tested by evaluating the results with the experimental results given in the literature.

\section{COMPOSITE FRAME DESCRIPTION -NUMERICAL ANALYSIS}

A series of one-bay one-story frame models were adopted to inspect the influence of different factors on the performance of the composite frame structures having CFDST columns connected to steel beam. Seven axial load ratios, four slenderness ratios of the column, and five linear stiffness ratios of the beam-column were considered during the modeling. These parameters are considered as the following:

-Axial force ratio $(\mathrm{n})$ of CFDST columns varies as 0 , $0.1,0.3,0.5,0.7,0.9$, and 1.1. It is defined as $n=\left(\mathrm{N}_{\mathrm{o}} / \mathrm{N}_{\mathrm{u}}\right)$ where $\mathrm{N}_{\mathrm{o}}$ is the column axial force and $\mathrm{N}_{\mathrm{u}}$ is the column axial compression capacity mentioned in Eurocode 4 (2004) as:

$$
\mathrm{N}_{\mathrm{u}}=\mathrm{f}_{\mathrm{yso}} \mathrm{A}_{\mathrm{so}}+\mathrm{f}_{\mathrm{ysi}} A_{\mathrm{si}}+\mathrm{f}_{\mathrm{c}} \mathrm{A}_{\mathrm{c}}
$$

in which $A_{\text {so }}$ and $A_{\text {si }}$ are cross sectional area of the outer and inner steel tubes, respectively. $\mathrm{f}_{\mathrm{yso}}$ and $\mathrm{f}_{\mathrm{ysi}}$ are steel yield stress for outer and inner tubes, respectively. 
$f_{c}$ is concrete compressive strength and $A_{c}$ is cross sectional area of the concrete.

-Slenderness ratio $(\lambda)$ of CFDST columns is $24,48,72$, and 96 and defined as the height to outer diameter of the column (4H/Do) based on DL/T 5085 (1999).

-Linear stiffness ratio $(\mathrm{k})$ of beam to column is $1.8,3.0$, $4.2,5.4$, and 6.6. It is given as $i_{B} / i_{c}$. $i_{B}$ is $E_{s} I_{e q} / l_{b}$ in which $\mathrm{I}_{\text {eq }}$ is the transformed section moment of inertia based on GB 50017 (2003) while $l_{b}$ is the steel beam length. $i_{c}$ is $\mathrm{E}_{\mathrm{h}} \mathrm{I}_{\mathrm{h}} / \mathrm{H}$. The stiffness of the circular CFDST column $\left(\mathrm{E}_{\mathrm{h}} \mathrm{I}_{\mathrm{h}}\right)$ as per AISC-LRFD (1999) is:

$$
E_{h} I_{h}=E_{s} I_{s}+0.8 E_{c} I_{c}
$$

In which $E_{s}$ and $E_{c}$ are the elastic modulus of steel tubes (outer and inner) and concrete, respectively. $\mathrm{I}_{\mathrm{s}}$ is the moment of inertia of outer and inner tubes while $I_{c}$ is the concrete moment of inertia.

Thus, sixteen different frame cases were generated and analyzed by using ANSYS FE software (ANSYS, 2016). The nonlinear static analysis was carried out to obtain the load-displacement response. Table 1 displays the characteristics of the composite frames and the key related parameters studied. CFDST columns with outer and inner circular sections and steel beam of I section were utilized. The yield strength for the steel tubes and steel beam is $290 \mathrm{MPa}$ and the infill concrete compressive strength is $28 \mathrm{MPa}$. Fig. 3 indicates the details of the frame under investigation while Fig. 4 depicts the corresponding frame and connections in the model.

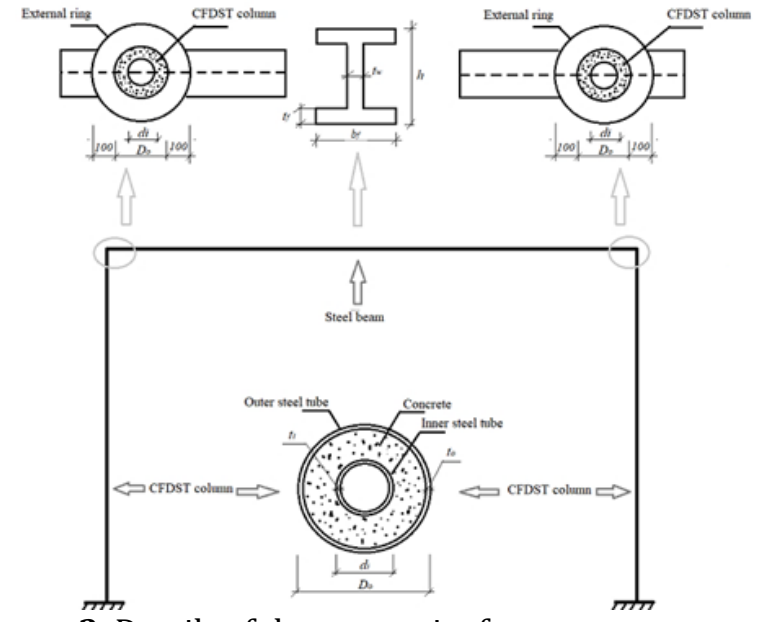

Figure 3. Details of the composite frame
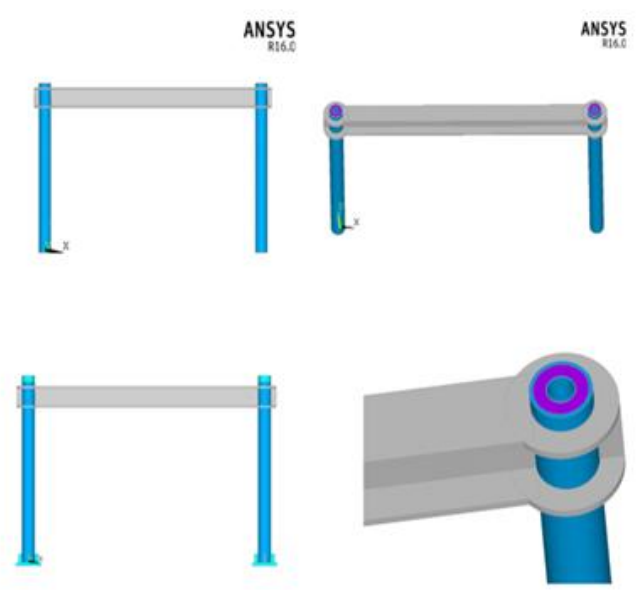

Figure 4. General view of the frame model

Table 1. Properties of the composite frames and related parameters

\begin{tabular}{|c|c|c|c|c|c|c|}
\hline Frame no. & Member & $h \times b_{f} \times t_{w} \times t_{f} / D_{o} \times t_{s o}-d_{i} \times t_{s i} \quad(\mathrm{~mm})$ & $L(\mathrm{~mm})$ & $\boldsymbol{k}$ & $n$ & $\lambda$ \\
\hline 1 & Beam/Column & $340.61 \times 314.96 \times 20 \times 31.75 / \Phi 254 \times 14.76-\Phi 120 \times 3.70$ & $4775 / 3048$ & 3.0 & 0 & 48 \\
\hline 2 & Beam/Column & $340.61 \times 314.96 \times 20 \times 31.75 / \Phi 254 \times 14.76-\Phi 120 \times 3.70$ & $4775 / 3048$ & 3.0 & 0.1 & 48 \\
\hline 3 & Beam/Column & $340.61 \times 314.96 \times 20 \times 31.75 / \Phi 254 \times 14.76-\Phi 120 \times 3.70$ & $4775 / 3048$ & 3.0 & 0.3 & 48 \\
\hline 4 & Beam/Column & $340.61 \times 314.96 \times 20 \times 31.75 / \Phi 254 \times 14.76-\Phi 120 \times 3.70$ & $4775 / 3048$ & 3.0 & 0.5 & 48 \\
\hline 5 & Beam/Column & $340.61 \times 314.96 \times 20 \times 31.75 / \Phi 254 \times 14.76-\Phi 120 \times 3.70$ & $4775 / 3048$ & 3.0 & 0.7 & 48 \\
\hline 6 & Beam/Column & $340.61 \times 314.96 \times 20 \times 31.75 / \Phi 254 \times 14.76-\Phi 120 \times 3.70$ & $4775 / 3048$ & 3.0 & 0.9 & 48 \\
\hline 7 & Beam/Column & $340.61 \times 314.96 \times 20 \times 31.75 / \Phi 254 \times 14.76-\Phi 120 \times 3.70$ & $4775 / 3048$ & 3.0 & 1.1 & 48 \\
\hline 8 & Beam/Column & $535.94 \times 210.06 \times 10.92 \times 17.45 / \Phi 254 \times 5.25-\Phi 120 \times 3.50$ & $4775 / 1524$ & 3.0 & 0.5 & 24 \\
\hline 9 & Beam/Column & $340.61 \times 314.96 \times 20 \times 31.75 / \Phi 254 \times 14.76-\Phi 120 \times 3.70$ & $4775 / 3048$ & 3.0 & 0.5 & 48 \\
\hline 10 & Beam/Column & $322.83 \times 308.86 \times 13.97 \times 22.866 / \Phi 254 \times 14.76-\Phi 120 \times 3.70$ & $4775 / 4572$ & 3.0 & 0.5 & 72 \\
\hline 11 & Beam/Column & $281.94 \times 262.63 \times 17.27 \times 28.24 / \Phi 254 \times 14.76-\Phi 120 \times 3.70$ & $4775 / 6096$ & 3.0 & 0.5 & 96 \\
\hline 12 & Beam/Column & $340.61 \times 314.96 \times 20 \times 31.75 / \Phi 254 \times 14.76-\Phi 120 \times 3.70$ & $7950 / 3048$ & 1.8 & 0.5 & 48 \\
\hline 13 & Beam/Column & $340.61 \times 314.96 \times 20 \times 31.75 / \Phi 254 \times 14.76-\Phi 120 \times 3.70$ & $4775 / 3048$ & 3.0 & 0.5 & 48 \\
\hline 14 & Beam/Column & $340.61 \times 314.96 \times 20 \times 31.75 / \Phi 254 \times 14.76-\Phi 120 \times 3.70$ & $3340 / 3048$ & 4.2 & 0.5 & 48 \\
\hline 15 & Beam/Column & $340.61 \times 314.96 \times 20 \times 31.75 / \Phi 254 \times 14.76-\Phi 120 \times 3.70$ & $2650 / 3048$ & 5.4 & 0.5 & 48 \\
\hline 16 & Beam/Column & $340.61 \times 314.96 \times 20 \times 31.75 / \Phi 254 \times 14.76-\Phi 120 \times 3.70$ & $2170 / 3048$ & 6.6 & 0.5 & 48 \\
\hline
\end{tabular}

\section{FE MODELING}

CFDST column under axial concentric loading results in a triaxial compression in the infill concrete. At later stage of loading, the concrete begins to soften and dilate, expanding radially, and applying lateral pressure on the steel tubes. Load applied in the axial direction and lateral pressure from the concrete put the steel tubes under biaxial stresses. So that, the real behavior of steel tubes and infill concrete are required in the FE model (Liang, 2017). Confinement of concrete by steel tubes enhances the strength capacity of composite column and ductility 
of concrete. Fig. 5 shows the full behavior of stress-strain curve for concrete in case of unconfinement and confinement (Pagoulatou et al., 2014).

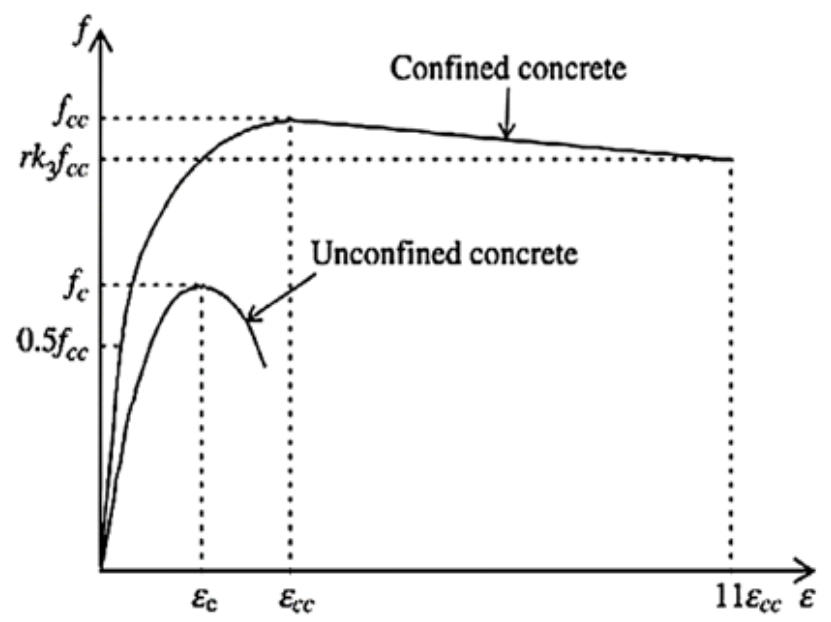

Figure 5. Equivalent uniaxial stress and strain relationship of the concrete (Pagoulatou et al., 2014)

Poisson's ratio of the concrete varies between 0.15 and 0.20 and depends on the concrete compressive strength. For small loads, steel tubes have no confinement effects on the infill concrete because the
Poisson's ratio of concrete is lower than of that of steel tubes. The strain and compressive strength of the unconfined concrete are named $\varepsilon_{c}$ and $f_{c}$, respectively. The strain varies in the range between 0.002 and 0.003 based on the ACI-318 (2014). The strain in the studied models is equal to 0.003 as maximum strain in the concrete. Due to loading, concrete begins to dilate and expands radially so that there is a rising in strain and compressive strength of concrete. Based on the Mander et al. (1988) and adopted by ACI-440-2R (2002), the relationship between confined and unconfined strain and compressive strength of concrete is given as:

$$
\begin{gathered}
f_{c c}=f_{c}+k_{1} f_{l} \\
\varepsilon_{c c}=\varepsilon_{c}\left(1+k_{2} \frac{f_{l}}{f_{c}}\right)
\end{gathered}
$$

The coefficients $k_{1}$ and $k_{2}$ are constants. In this study, the coefficients $k_{1}$ and $k_{2}$ are set to 4.1 and 20.5 based on the studies of Richart et al. (1928), Hu and Schnobrich (1989), Hu and Su (2011), and Pagoulatou et al. (2014). The average radial pressure $f_{l}$ depends on the ratio of diameter to thickness of outer and inner tubes and it can be calculated by the following empirical formula ( $\mathrm{Hu}$ and $\mathrm{Su}, 2011)$ :

$$
f_{l}=8.525-0.166\left(\frac{D_{o}}{t_{o}}\right)-0.00897\left(\frac{D_{i}}{t_{i}}\right)+0.00125\left(\frac{D_{o}}{t_{o}}\right)^{2}+0.00246\left(\frac{D_{o}}{t_{o}}\right) \times\left(\frac{D_{i}}{t_{i}}\right)-0.00550\left(\frac{D_{i}}{t_{i}}\right)^{2}
$$

$D_{o}$ and $D_{i}$ are the outer and inner tube diameters, respectively, while $t_{o}$ and $t_{i}$ are the outer and inner tube thicknesses, respectively.

To determine the nonlinear behavior of concrete, the following equation suggested by Saenz (1964) is utilized:

$$
\sigma=\frac{E_{c c} \varepsilon}{1+\left(R+R_{E}-2\right)\left(\frac{\varepsilon}{\varepsilon_{c c}}\right)-(2 R-1)\left(\frac{\varepsilon}{\varepsilon_{c c}}\right)^{2}+R\left(\frac{\varepsilon}{\varepsilon_{c c}}\right)^{3}}
$$

In which the modulus elasticity $E_{c c}$ (defined in ACI (1999)), $R$, and $R_{E}$ could be calculated using the following equations:

$$
\begin{gathered}
E_{c c}=4700\left(\sqrt{f_{c c}}\right) \\
R_{E}=\frac{E_{c c} \varepsilon_{c c}}{f_{c c}} \\
R=\frac{R_{E}\left(R_{\sigma}-1\right)}{\left(R_{\varepsilon}-1\right)}-\frac{1}{R_{\varepsilon}}
\end{gathered}
$$

In which $R_{\sigma}$ (stress relation) $=f_{c}^{\prime} / \sigma_{f}$ and $R_{\varepsilon}$ (strain relation) $=\varepsilon_{f} / \varepsilon_{c}$ where $\varepsilon_{f}$ and $\sigma_{f}$ are the maximum strain and the corresponding stress, respectively. Generally, defining $\varepsilon_{f}$ and $\sigma_{f}$ is difficult since the descending branch of the stress-strain curve is greatly test-dependent and is usually unavailable from statically determinate tests $\mathrm{CH}$ and Schnobrich, 1989). On the other hand, in the literature, Darwin and Pecknold (1974) used $R_{\sigma}=5$ and $R_{\varepsilon}=4$ while Elwi and Murray (1979), Chen (1981) and $\mathrm{Hu}$ and Schnobrich (1989) used $R_{\sigma}=4$ and $R_{\varepsilon}=4$. In this study, it is assumed that $R_{\sigma}=4$ and $R_{\varepsilon}=4$.

To be able to determine the last point of the descending zone in stress-strain relation of the concrete, the formula $r k_{3} f_{c c}$ was utilized. It takes into consideration the final stress value before failure that corresponds to strain value of $11 \varepsilon_{c c}$. Moreover, $k_{3}$ is the confined concrete degradation factor and the following formula suggested by $\mathrm{Hu}$ and $\mathrm{Su}$ (2011) is used:

$$
k_{3}=1.73916-0.00862\left(\frac{D_{o}}{t_{o}}\right)-0.04731\left(\frac{D_{i}}{t_{i}}\right)-0.00036\left(\frac{D_{o}}{t_{o}}\right)^{2}+0.00134\left(\frac{D_{o}}{t_{o}}\right) \times\left(\frac{D_{i}}{t_{i}}\right)-0.0058\left(\frac{D_{i}}{t_{i}}\right)^{2}
$$

The nonlinear behavior of steel is adopted based on the stress-strain relationship. This relation is supposed to be elastic till a yield point and then perfectly plastic. When the internal stress due to applied load goes beyond the yield stress $\left(f_{y}\right)$, the steel section exhibits plastic deformation. The relationship between the stress and strain in the numerical analysis is supposed as a linear with a slope of $E_{s}$ until a yield period and after that the slope change to $0.1 \mathrm{E}_{\mathrm{s}}$ to enhance the stability analysis. The Von-Misses failure criterion given in the equation 11 was considered applicable for modeling steel yielding under multiple stresses ( $\mathrm{Hu}$ and $\mathrm{Su}, 2011$ ). 


$$
\left(\sigma_{1}-\sigma_{2}\right)^{2}+\left(\sigma_{1}-\sigma_{3}\right)^{2}+\left(\sigma_{2}-\sigma_{3}\right)^{2}=2 f_{y}^{2}
$$

Two types of elements are considered to simulate the frame model. SOLID65 element is utilized for concrete, and SOLID186 for steel tubes, I beam, and steel end plates. The selected elements represent and simulate the actual behavior of the materials. The solid element Solid65 for concrete contains eight nodes having three degrees of freedom at each node and translations in the nodal $\mathrm{x}, \mathrm{y}$, and $\mathrm{z}$ directions. Solid65 performs plastic deformation, cracking in three orthogonal directions, and crushing. The geometry, node locations, and the coordinate system for this element are shown in Figure 6. The steel solid element SOLID 186 is a higher order 3D 20-node element, which performs quadratic displacement response. The geometry, node locations, and the coordinate system for this element are shown in Figure 7. Moreover, the conditions of the loading utilized in the models are the constant axial force (equally distributed through the nodes) and increasing lateral load applied at one end of the beam (equally distributed owing to the nodes) till failure. The conditions of the support are considered as restrained in all directions ( $\mathrm{x}$, $y$ and $z$ ) with the aim of being as fixed.

The steel tube and the infill concrete interface was modeled using contact elements that represent the actual behavior of the composite column taking into account the friction effect and slips. The contact elements transfer the force between the steel tubes (inner and outer) and the infill concrete because of the friction at the contact surface, thus the composite action is achieved. Friction force developed at the contact surface reduces the shear stress and slips. The friction coefficient between the concrete and steel is 0.6 as used by Han et al. (2011).

\section{VERIFICATION OF FE MODEL}

With the purpose of verifying the validity of the developed FE models, two CFDST columns (namely, pcc1-2a and pcc2-2a) tested by Tao et al. (2004) were modeled. Load, geometries, and other parameters that adopted by Tao et al. (2004) were used and simulated. The analysis results were taken at the dial gauge locations as in the experimental tests. Fig. 8 illustrates FE modeling of pcc1-2a specimen. Fig. 9 indicates the buckled specimen after the test and FE model with displacement vector distributions along the height of the column pcc1-2a obtained in this study. Moreover, FE displacement results of Pcc2-2a specimen is illustrated in Fig. 10. The lateral displacements along the column height of the test specimens and FE models are drawn in Figs. 11 and 12. It was observed that the FE modeling results were in good agreement with the experimental ones in terms of the lateral displacements. At the initial loading period, the lateral displacements (buckling) at the middle of column were very little and almost proportional to the load applied. Once the load increased and reached nearby $68 \%$ of the ultimate load, the lateral displacements at middle increased significantly with shape of half sine wave as also reported in the experimental work of Tao et al. (2004). FE results in comparison with experimental test results showed less in magnitude due to a rigid body of model nodes. Tables
2 and 3 demonstrate the results of the experiments and FE analysis for both of the specimens pcc1-2a and pcc2$2 a$. It can be concluded from the tables that the results based on the FE modeling were in line with the experimental ones.

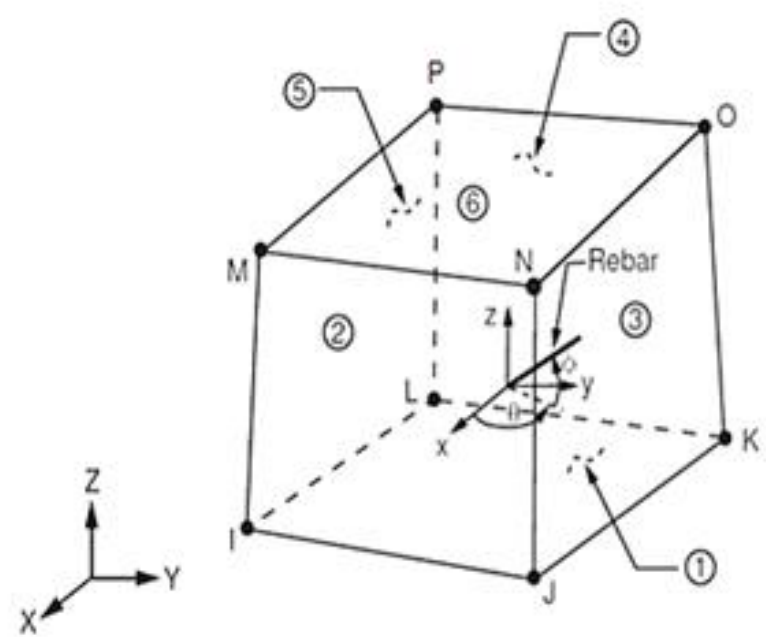

Figure 6. SOLID65 geometry (ANSYS, 2016)

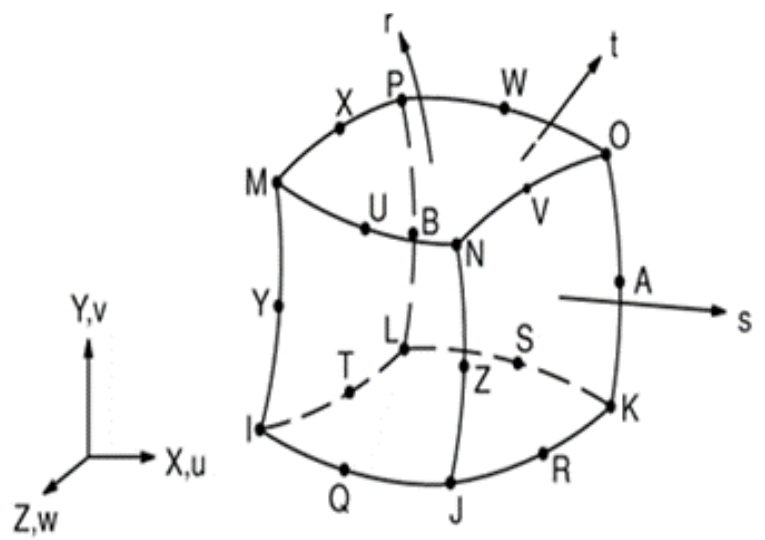

Figure 7. SOLID186 geometry (ANSYS, 2016)

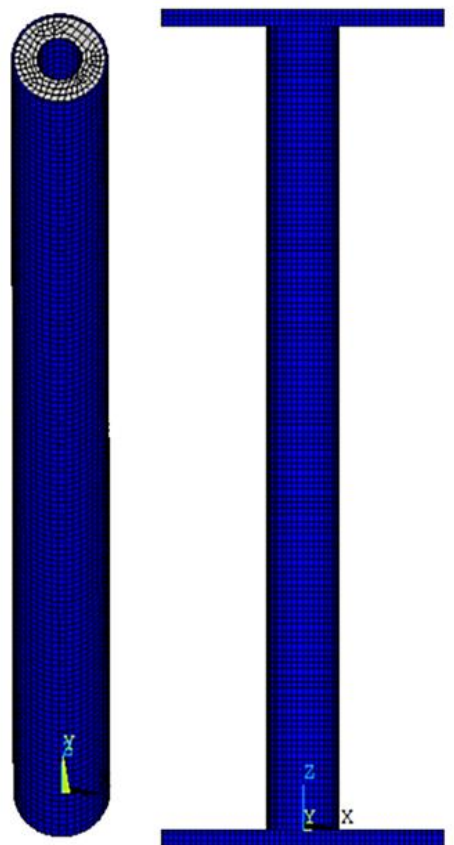

Figure 8. FE modeling of pcc1-2a specimen tested in the study of Tao et al. (2004) 


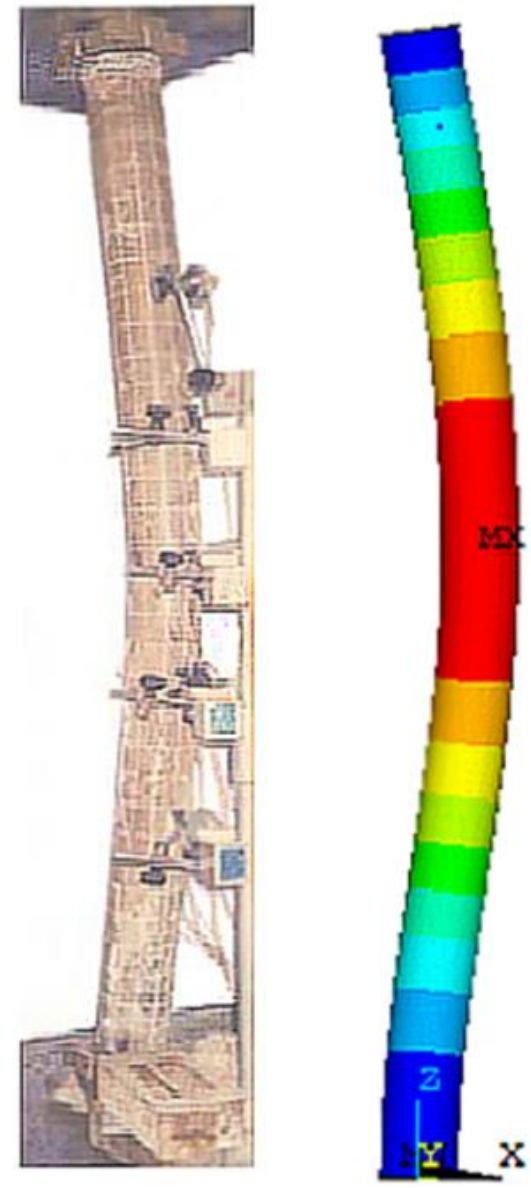

Figure 9. Buckled specimen (pcc1-2a) tested by Tao et al. (2004) and the developed FE model

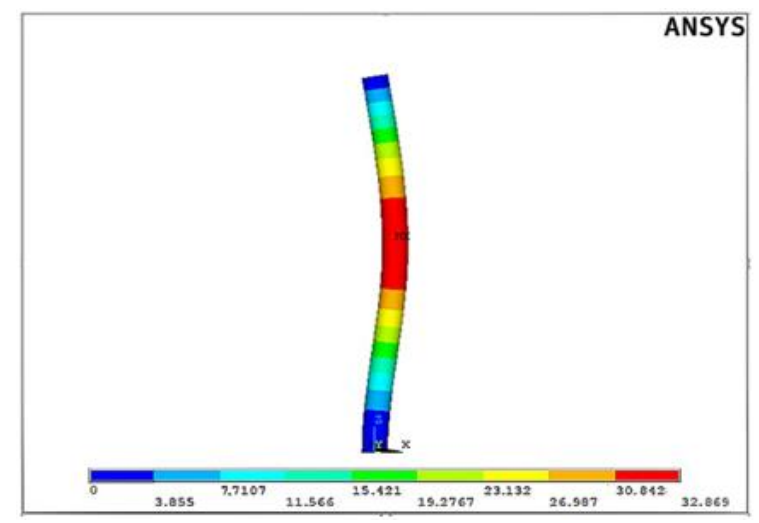

Figure 10. Displacement results of pcc2-2a specimen of Tao et al. (2004) (in mm)

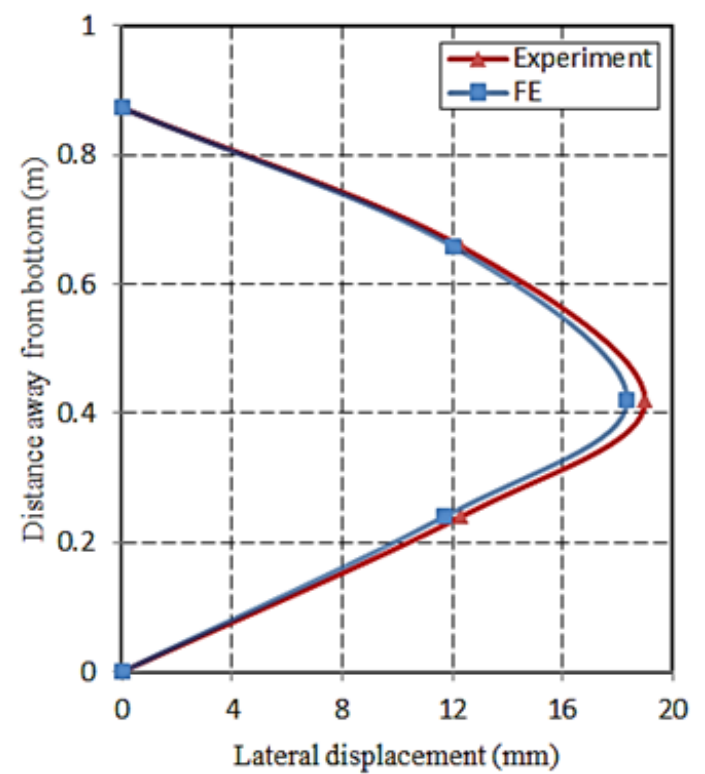

Figure 11. Lateral displacement along the column height of experimentally tested specimen (pcc1-2a) of Tao et al. (2004) and the developed FE model

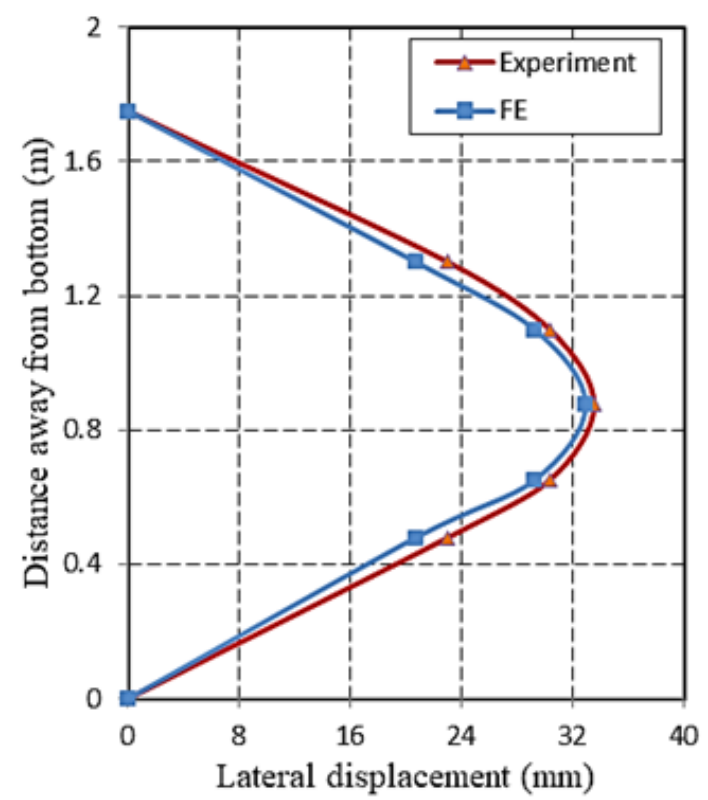

Figure 12. Lateral displacement along the column height of experimentally tested specimen (pcc2-2a) of Tao et al. (2004) and the developed FE model

Table 2. Experimental and numerical results for the specimen pcc1-2a of Tao et al. (2004)

\begin{tabular}{cccc}
\hline Item & $\begin{array}{c}\text { Experimental } \\
\text { result (Tao et al., 2004) }\end{array}$ & FE model result & $\frac{\text { Theoretical }}{\text { Experimental }}(\%)$ \\
\hline Ultimate load $(\mathrm{kN})$ & 620 & 636 & 102.6 \\
$\begin{array}{c}\text { Max. lateral displacement } \\
\text { (Buckling) (mm) }\end{array}$ & 19 & 18.54 & 97.6 \\
\hline
\end{tabular}

Table 3. Experimental and numerical results for the specimen pcc2-2a of Tao et al. (2004)

\begin{tabular}{cccc}
\hline Item & $\begin{array}{c}\text { Experimental } \\
\text { result (Tao et al., 2004) }\end{array}$ & FE model result & $\frac{\text { Theoretical }}{\text { Experimental }}(\%)$ \\
\hline Ultimate load $(\mathrm{kN})$ & 400 & 409 & 102.3 \\
Max. lateral displacement & 33.5 & 32.86 & 98.1 \\
(Buckling) (mm) & & & \\
\hline
\end{tabular}




\section{RESULTS AND DISCUSSION}

All frames were modeled and meshed depending on the verification model. Fig. 13 represents the typical frame and beam-column connection meshing. Several parameters were considered in FE analysis. They were listed as the axial load and slenderness ratios of CFDST column and the ratio of the linear stiffness of the beamcolumn. The effects of these parameters on the lateral response of the composite frames were evaluated and discussed.

The ratio of axial load (n) were adopted as $0,0.1,0.3$, $0.5,0.7,0.9$ and 1.1 while other parameters remained constant as given in Table 1 (Frame no: 1 to 7). Fig. 14 represents the lateral load vs. displacement relationship for different axial load ratios. The performance started as linear up to a point of inflection that relay on the applied load. The curves became nonlinear as the load increased beyond the inflection point due to decreasing in the system stiffness that led to increase in displacements. It was noted that the maximum lateral load increased with the rise of $n$ value (from 460 to $860 \mathrm{kN}$ ) and concomitant a decrease in the ductility of the frame. Moreover, increasing $n$ value from 0 to 1.1 resulted in increasing the initial stiffness from 8.3 to $18.3 \mathrm{kN} / \mathrm{mm}$. It was also observed that there was an increase of initial stiffness for the ratios of the axial load between 0 and 0.5 while the close values of initial stiffness were found for the ratios of the axial load from 0.5 to 1.1 .

The column slenderness $(\lambda)$ has the values of 24,48 , 72 and 96 while the other parameters are held fixed as presented in Table 1 (Frame no: 8 to 11). In all models, the same column cross-section is used (same moment of inertia) so that only the column height affects the slenderness ratio with same boundary conditions of supports. In this case, the lateral displacement increased as the slenderness ratio increased for the same applied axial load as depicted in Fig. 15. The ratio of the column slenderness is very important parameter for the buckling and stability, the rise in the height of the column caused to increase the buckling due to the reduction in strength against lateral and axial loads. The ultimate lateral load capacity and the corresponding initial stiffness values varied from 311 to $1120 \mathrm{kN}$ and from 3.8 to $82.1 \mathrm{kN} / \mathrm{mm}$, respectively. With increasing the slenderness of the column, the yield load and ultimate load had a tendency to decrease. For the slenderness ratios of 48,72 and 96 , the ultimate load diminishes 1.44, 2.38 and 3.19 times, respectively as compared with the slenderness ratio of 24.

For studying the effect of the linear stiffness ratio $(k)$ of the beam-column on the response of the frame structure, the length of the steel beam was altered while the other investigation parameters are held constant as seen in Table 1 (Frame no: 12 to 16). Fig. 16 represents the displacement that occurs due to the applied lateral load with different ratios of the beam-column linear stiffness. The load-displacement behavior was linear tendency up to a point then became nonlinear due to the strength reduction, which resulted more displacements. The increment in the beam-column linear stiffness ratio made the composite frame more stable and could carry more load as shown in Fig. 16. It could be noticed that the load capacity increased from 673 to $978 \mathrm{kN}$ with the increase of $k$ from 1.8 to 6.6. In addition, it can be noted that the initial stiffness increased from 11.7 to 29.7 as $k$ increased from 1.8 to 6.6 .

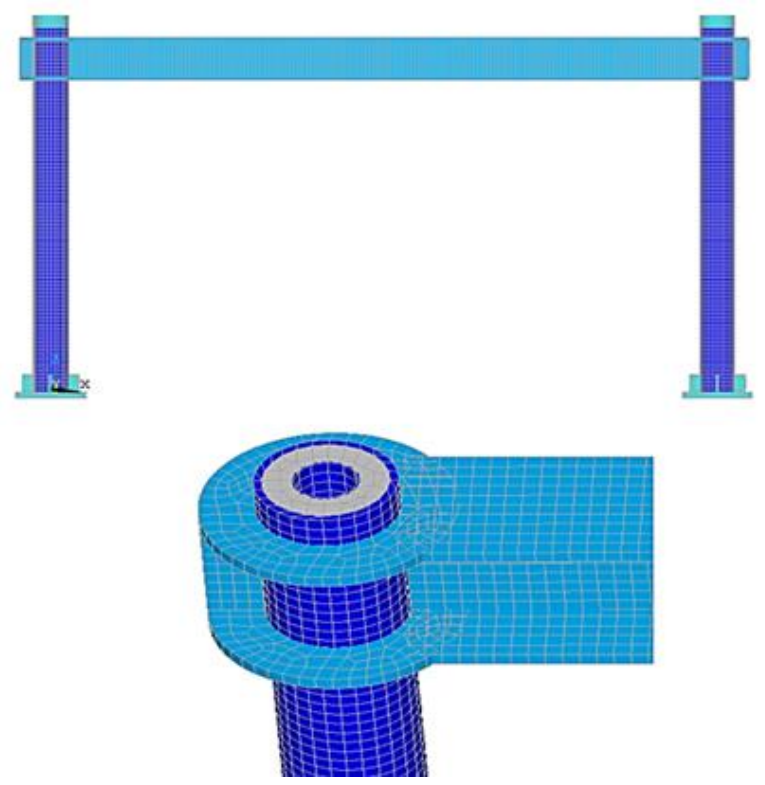

Figure 13. Meshing of frame and beam-column connection

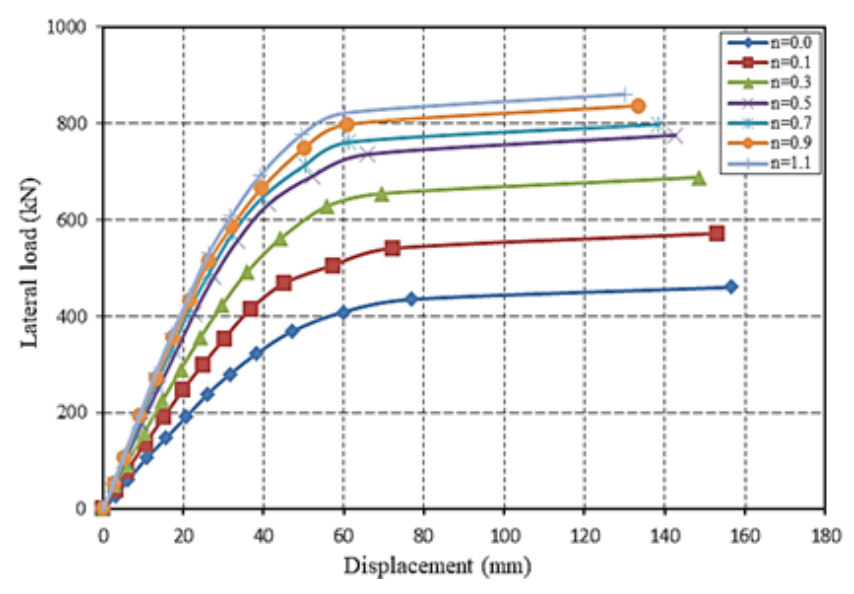

Figure 14. Load-displacement relationship for all frame models with different axial load ratios

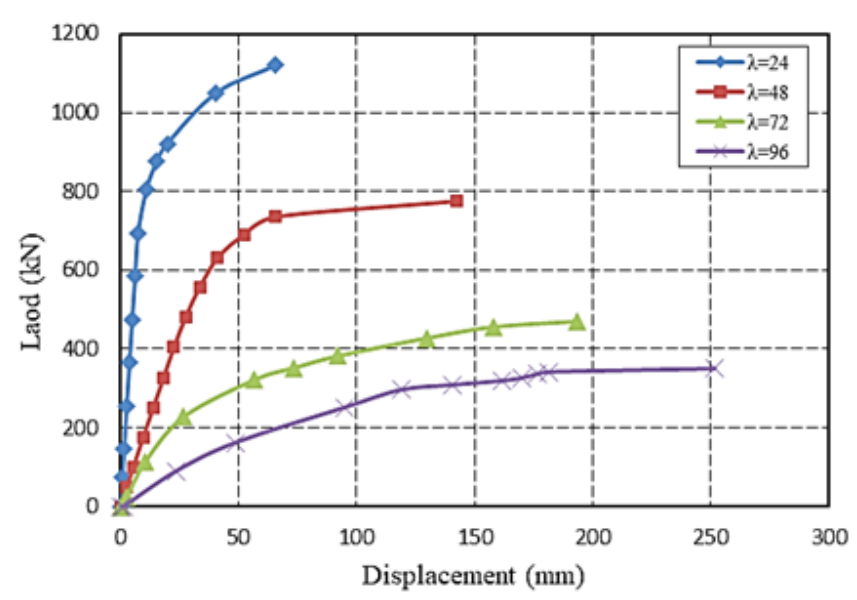

Figure 15. Load-displacement relationship for all frame models with different slenderness ratios 


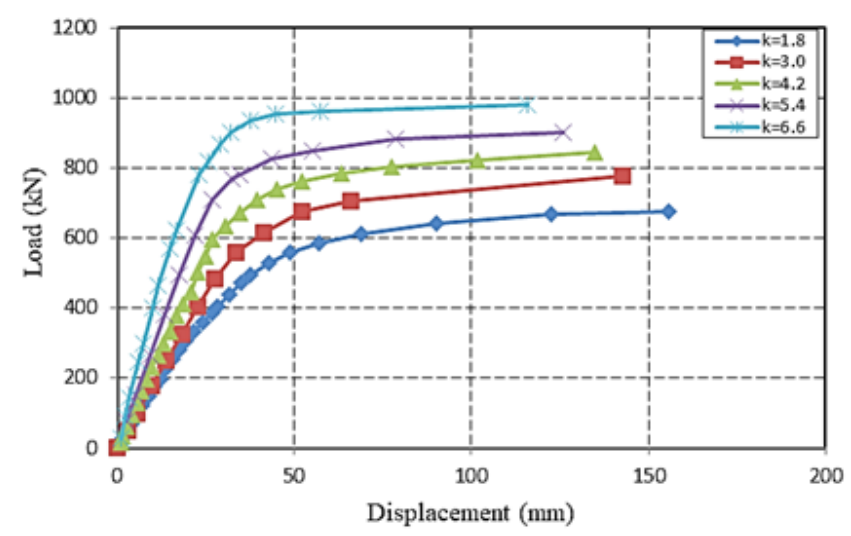

Figure 16. Load-displacement relationship for all frame models with different beam-column linear stiffness ratios

The area underneath the curve of the loaddisplacement is defined as the toughness of the frame. The variation of the toughness with various key parameters under the investigation is shown in Fig. 17. As the axial load ratio (n) increased from 0 to 0.5 , an increase in toughness was observed (49\% increment). While little increase in the toughness for 0.5 to $1.1(1.9 \%$ increment) was detected. It could be figured out that as $n$ increased, the composite frame displayed both improved strength and ductility. By way of the ratio of the column slenderness $(\lambda)$ raised, an improvement in the value of the toughness was observed. Increasing $\lambda$ from 24 to 48 resulted in higher toughness (40\% increment) while the toughness decreased by $32 \%$ for $\lambda$ from 48 to 96 . Moreover, since the stiffness ratio of the beam-column $(k)$ increased, the toughness was gradually increased. For example, in the case of $k$ raised from 1.8 to 6.6 , more than $16 \%$ increment in the toughness was recorded. It could be concluded that a greater ratio of the beam-column linear stiffness might cause higher capacity of the energy absorption. As a result, the variation in the axial load, slenderness, and stiffness ratios considerably influenced the load-displacement demand of the composite frames, which provide different values of the toughness.

The statistical analysis of the studied parameters was also performed. The general linear model analysis of variance based on the statistical Minitab Software (Minitab R12) was used to analyze the data resulted from the study. Each parameter (n, $\lambda$, and $\mathrm{k}$ ) was considered as an independent variable and the analysis result such as the maximum load carrying capacity of the composite frame was considered as a dependent variable. The evaluation is made using the P-value that obtained as a result of the statistical analysis. Table 4 represents the results obtained by the software analysis.

The calculated P-values of the maximum load give an important indication for the studied cases. When P-value less than $5 \%$ (significance level) indicates that, there is an effect of that independent variable on the analysis results. In the case of $\mathrm{P}$-value more than $5 \%$ indicates that an independent variable has no effect on the analysis results. From the table, it could be concluded that there is a significant effect of each of independent variables (n, $\lambda$, and $\mathrm{k}$ ) on the corresponding dependent variable of the maximum lateral load carrying capacity of the case study frames.
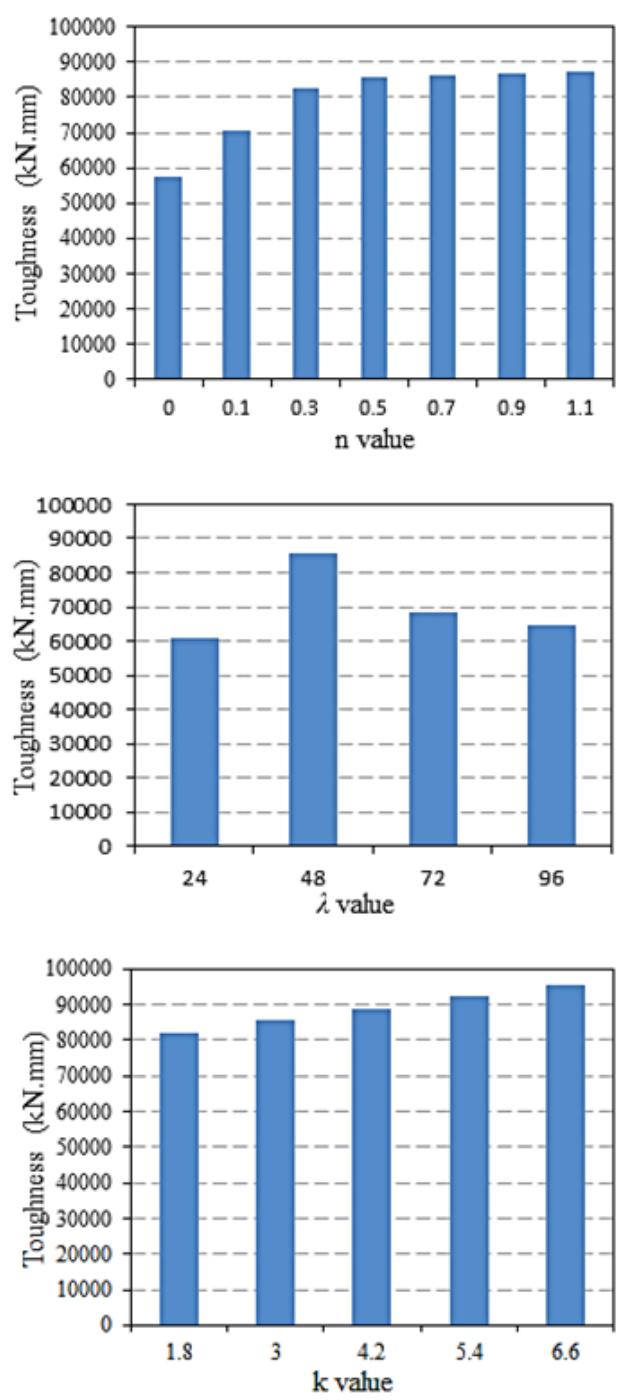

Figure 17. Variation of the toughness with various parameters

Table 4. Statistical analysis for the maximum load carrying capacity

\begin{tabular}{|c|c|c|c|c|c|c|}
\hline $\begin{array}{l}\text { Dependent } \\
\text { variable }\end{array}$ & $\begin{array}{l}\text { Independent } \\
\text { variable }\end{array}$ & $\begin{array}{l}\text { Sequential sum } \\
\text { of squares }\end{array}$ & $\begin{array}{l}\text { Mean } \\
\text { square }\end{array}$ & Computed F & P-value & Significance \\
\hline \multirow{9}{*}{$\begin{array}{l}\text { Maximum } \\
\text { load }\end{array}$} & Axial load ratio (n) & 116644.2 & 116644.2 & 36.003 & 0.002 & Yes \\
\hline & Error & 16199.2 & 3239.8 & - & - & - \\
\hline & Total & 132843.4 & - & & - & - \\
\hline & Slenderness ratio $(\lambda)$ & 373409.8 & 373409.8 & 82.167 & 0.012 & Yes \\
\hline & Error & 9089.0 & 4544.5 & - & - & - \\
\hline & Total & 382498.8 & - & - & - & - \\
\hline & Linear stiffness ratio (k) & 54290.4 & 54290.4 & 357.342 & 0.000 & Yes \\
\hline & Error & 455.8 & 151.9 & - & - & - \\
\hline & Total & 54746.2 & - & - & - & - \\
\hline
\end{tabular}




\section{CONCLUSIONS}

The structural behavior of composite frames having CFDST columns and I steel beam is studied in the present research. The frames are subjected to lateral load till failure. ANSYS FE software is used for modeling and analyzing the frames. The following conclusions could be summarized below:

-According to the findings of the work, there is no confinement effect of inner and outer steel tube to the infill concrete at initial loading. In the case of the applied load raised, both of the longitudinal and transverse strains increase, thus the concrete lateral expansion progressively becomes higher than that of the inner and outer steel tubes. The infill concrete delays the local buckling of the steel tubes and decreases the buckling at the final period of the loading. Similar failure mode is observed for all composite frames studied. Plastic hinges are developed at two ends of the CFDST columns and there is no concrete crushing was noticed.

-From the results, it could be pointed out that the maximum lateral load increases with increasing the axial load ratios while the initial stiffness increases only with small axial load ratios. There is an increase in the lateral stiffness and lateral load capacity of the composite frame as the CFDST column slenderness ratio decreases. Moreover, the initial stiffness and load capacity increase with the increase of the beam-column stiffness ratio.

-It can be drawn that the composite frame exhibits higher toughness, which is systematically increasing, owing to the increment in the axial load ratio of the column and linear stiffness ratio of the beam-column.

-The statistical analysis clearly shows that there is a significant impact of the parameters studied on the maximum load carrying capacity of the composite frame.

\section{Author contributions}

Ahmed Dalaf Ahmed: Conceptualization, Methodology, Software, Writing. Esra Mete Güneyisi: Visualization, Investigation, Reviewing and Editing.

\section{Conflicts of interest}

The authors declare no conflicts of interest.

\section{REFERENCES}

ANSYS (2016). ANSYS User's Manual Revision 16.0 ANSYS, Inc., Canonsburg, Pennsylvania.

Load A I S C (1999). Resistance Factor Design Specification for Structural Steel Buildings. American Institute of Steel Construction: Chicago, IL, USA.

ACI (2014). Building Code Requirements for Structural Concrete (ACI 318-14): Commentary on Building Code Requirements for Structural Concrete (ACI 318R-14): an ACI Report. American Concrete Institute. ACI.

ACI (2002). 440.2 R-02: Guide for the design and construction of externally bonded FRP systems for strengthening concrete structures. American Concrete Institute, Farmington Hills, USA.
ACI. (1999). Building code requirements for structural concrete and commentary, ACI 318-399. American Concrete Institute, Detroit, USA.

Bradford M A, Loh H Y \& Uy B (2002). Slenderness limits for filled circular steel tubes. Journal of Construction Steel Research, 58(2), 243-252.

Chen E Y-T (1981). Numerical simulation of reinforced concrete subjected to multiaxial stress conditions. $\mathrm{PhD}$ Thesis, University of Illinois

Darwin D \& Pecknold D A (1974). Inelastic model for cyclic biaxial loading for reinforced concrete. Civil Engineering Studies, Structural Research Series No. 409, Univ. of Illinois at Urbana-Champaign, UrbanaChampaign, 111.

DL/T 5085-1999, Code for Design of Steel-Concrete Composite Structure, China Planning Press, Beijing.

Elchalakani M, Zhao X L \& Grzebieta R (2002). Tests on concrete filled double skin (CHS outer and SHS inner) composite short columns under axial compression. Thin-Walled Structures, 40(5), 415441.

Elwi A A \& Murray D W (1979). A 3D hypoelastic concrete constitutive relationship. Journal of the Engineering Mechanics Division, 105(4), 623-641.

Eurocode 4, BS EN 1994-1-1-2004, Design of Composite Steel and Concrete Structures-Part 1.1 General Rules and Rules for Buildings, Brussels, Belgium.

GB 50017-2003, Code for Design of Steel Structures, China Planning Press, Beijing.

Han L H, Tao Z, Huang H \& Zhao X L (2004). Concretefilled double skin (SHS outer and CHS inner) steel tubular beam-columns. Thin-Walled Structures, 42(9), 1329-1355.

Han L H, Huang H, Tao Z \& Zhao X L (2006). Concretefilled double skin steel tubular (CFDST) beamcolumns subjected to cyclic bending. Engineering Structures, 28(12), 1698-1714.

Han L H, Wang W D \& Zhao X L (2011). Performance of circular CFST column to steel beam frames under lateral cyclic loading. Journal of Constructional Steel Research, 67(5), 876-890.

Hassanein M F, Kharoob O F \& Gardner L (2015). Behaviour and design of square concrete-filled double skin tubular columns with inner circular tubes. Engineering Structures, 100, 410-424.

$\mathrm{Hu} \mathrm{H} \mathrm{T} \& \mathrm{Su}$ F C (2011). Nonlinear analysis of short concrete-filled double skin tube columns subjected to axial compressive forces. Marine Structures, 24(4), 319-337.

Hu H T \& Schnobrich W C (1989). Constitutive modeling of concrete by using non associated plasticity. Journal of Materials in Civil Engineering, 1(4), 199216.

Huang H, Han L H, Tao Z \& Zhao X L (2010). Analytical behavior of concrete-filled double skin steel tubular (CFDST) stub columns. Journal of Constructional Steel Research, 66(9), 542-255.

Li W, Han L H \& Zhao X L (2012). Axial strength of concrete-filled double skin steel tubular (CFDST) columns with preload on steel tubes. Thin-walled structures, 56, 9-20.

Liang Q Q (2017). Nonlinear analysis of circular doubleskin concrete-filled steel tubular columns under 
axial compression. Engineering Structures, 131, 639-650.

Lin M L \& Tsai K C (2001). Behavior of double-skinned composite steel tubular columns subjected to combined axial and flexural loads. In: Proceedings of the first international conference on steel and composite structures, 1145-1152.

Lu H, Han L H \& Zhao X L (2010). Fire performance of selfconsolidating concrete filled double skin steel tubular columns: Experiments. Fire safety journal, 45(2), 106-115.

Mander J B, Priestley M J \& Park R (1988). Theoretical stress-strain model for confined concrete. Journal of structural engineering, 114(8), 1804-1826.

Minitab R12. Statistical Tool. Quality Plaza, 1829 Pine Hall Rd., State College, PA 16801-3008, USA.

Pagoulatou M, Sheehan T, Dai X H \& Lam D (2014). Finite element analysis on the capacity of circular concrete-filled double-skin steel tubular (CFDST) stub columns. Engineering Structures, 72, 102-112.

Richart F E, Brandtzaeg A \& Brown R L (1928). A study of the failure of concrete under combined compressive stresses. University of Illinois at Urbana Champaign, College of Engineering. Engineering Experiment Station.

Ritchie C B, Gow M I, Packer J A \& Heidarpour A (2017). Influence of elevated strain rate on the mechanical properties of hollow structural sections. International Journal of Protective Structures, 8(3), 325-351.

Saenz L P (1964). Discussion of "Equation for the stressstrain curve of concrete" by Desayi and Krishnan. Journal of the American Concrete Institute, 61, 12291235.

Tao Z, Han L H \& Zhao X L (2004). Behaviour of concretefilled double skin (CHS inner and CHS outer) steel tubular stub columns and beam-columns. Journal of Constructional Steel Research, 60(8), 1129-1158.

Uenaka K, Kitoh H \& Sonoda K (2010). Concrete filled double skin circular stub columns under compression. Thin-walled structures, 48(1), 19-24.
Wei S, Mau S T, Vipulanandan C \& Mantrala S K (1995). Performance of new sandwich tube under axial loading: experiment.Journal of Structural Engineering, 121(12), 1806-1814.

Yagishita F, Kitoh H, Sugimoto M, Tanihira T \& Sonoda K (2000). Double skin composite tubular columns subjected to cyclic horizontal force and constant axial force. In Proc., 6th ASCCS Int. Conf. on SteelConcrete Composite Structures, Los Angeles: Univ. of Southern California, 497-503.

Zhao X L, Grzebieta R H \& Elchalakani M. (2002a). Tests of concrete-filled double skin CHS composites tube columns. Steel and Composite Structures-An International Journal, 2(2), 129-142.

Zhao X L, Grzebieta R H, Ukur A \& Elchalakani M (2002b). Tests of concrete-filled double skin (SHS outer and CHS inner) composite stub columns. In Advances in Steel Structures (ICASS'02), Elsevier, 567-574.

Zhao X L \& Grzebieta R H (2002c). Strength and ductility of concrete filled double skin (SHS inner and SHS outer) tubes. Thin-Walled Structures, 40(2), 199213.

Zhao X L, Han B \& Grzebieta R H (2002d). Plastic mechanism analysis of concrete filled double-skin (SHS inner and SHS outer) stub columns. ThinWalled Structures, 40(10), 815-833.

Zhang Y \& Zhou Z (2019). Beam-column connections of concrete-filled double steel tubular frame structures. The Structural Design of Tall and Special Buildings, 28(5), e1592.

Zhang D, Zhao J \& Zhang Y (2018). Experimental and numerical investigation of concrete-filled doubleskin steel tubular column for steel beam joints. Advances in Materials Science and Engineering, 6514025 